Original Article

\title{
Effect of proprioception cross training on repositioning accuracy and balance among healthy individuals
}

\author{
Tarek Mohamed El-Gohary, PhD, PT, OCS, Cert.MDT, CEAS ${ }^{1,2)}$, \\ Osama Ahmed Khaled, PhD, $\mathrm{PT}^{1,3)^{*}}$, Sameh R Ibrahim, PhD, PT ${ }^{1,3)}$, \\ Abdullah M Alshenqiti, PhD, PT ${ }^{1)}$, Mahmoud I Ibrahim, PhD, PT ${ }^{4}$ \\ 1) Department of Physical Therapy, College of Medical Rehabilitation, Taibah University: PO Box 344, \\ Almadina Almunawara 41411, Saudi Arabia \\ 2) Department of Biomechanics, Faculty of Physical Therapy, Cairo University, Egypt \\ 3) Department of Basic Science, Faculty of Physical Therapy, Cairo University, Egypt \\ 4) Department of Orthopedic, Faculty of Physical Therapy, Cairo University, Egypt
}

\begin{abstract}
Purpose] To investigate possible cross effects of proprioception training on proprioception repositioning accuracy of the knee joint and on balance in healthy subjects. [Subjects and Methods] Sixty healthy college students and faculty members from faculty of physical therapy, Cairo University were recruited to participate. Participants were randomly assigned to training group $(n=30)$ and control group $(n=30)$. The training group received proprioceptive training program only for the dominant leg while the control group did not receive any kind of training. Outcome measures were twofold: (1) proprioception repositioning accuracy quantified through the active repositioning test for the non-dominant knee; and (2) balance stability indices determined through using Biodex balance system. Measurements were recorded before and after 8 weeks of proprioception training. [Results] There were significant decrease in the error of repositioning accuracy and the stability indices including anterposterior stability index, mediolateral stability index, and overall stability index of training group, measured post training, compared with control group. [Conclusion] Proprioception training has significant cross training effects on proprioception repositioning accuracy of the knee joint and on balance among healthy subjects.

Key words: Cross training, Repositioning accuracy, Balance
\end{abstract}

(This article was submitted May 27, 2016, and was accepted Jul. 29, 2016)

\section{INTRODUCTION}

Proprioceptive training has been extensively investigated in multiple studies ${ }^{1-4)}$. Proprioceptors are sensors that relay information about joint angle, muscle tension and muscle length to the central nervous system. Proprioception is responsible for collection of sensations regarding joint movement which is known as kinesthesia and collection of sensation regarding joint position. The proprioceptors also contribute in controlling posture and coordination through a complex reflex system ${ }^{5,6}$. Proprioceptive disorder is common in individuals with chronic joint instability ${ }^{6}$ ) and in patients with severe arthritis ${ }^{7)}$. Proprioception acuity becomes disrupted subsequent to any capsulo-ligamentous injury, articular musculoskeletal injury or surgery ${ }^{8)}$.

Proprioceptive training is an essential component of rehabilitation program in order to restore functional stability ${ }^{9}$. It is well stated in literature that proprioception training decreases the incidence of injuries, diminishes the postural sway and improves proprioception accuracy and strength in trained subjects more than non- trained subjects ${ }^{10-13)}$. Proprioceptive

\footnotetext{
*Corresponding author. Osama Ahmed Khaled (E-mail: Drosama179@yahoo.com)

C2016 The Society of Physical Therapy Science. Published by IPEC Inc.

This is an open-access article distributed under the terms of the Creative Commons Attribution Non-Commercial No Derivatives (by-nc-nd) License $<$ http://creativecommons.org/licenses/by-nc-nd/4.0/>.
} 
training program is recommended for prevention and rehabilitation of recurrent and chronic joint instability. Moreover, it can be integrated in the regular training program ${ }^{6}$. However; joint immobilization, pain and inflammation might limit proprioception training. Therefore; training of the contralateral unaffected limb could be a solution. It is often claimed that unilateral strength training can induce positive effects in the untrained limb, which is called contralateral strength training effect or cross training ${ }^{14)}$. The central nervous system could take the pattern of motor control established through training the non-injured leg and apply it completely to the injured leg to expedite the process of return to normalcy once training is resumed $^{6}$. The neurophysiologic mechanisms include, but is not limited to, cross education, the increase of the neural drive from motor cortex and the spillover to the control system of the untrained leg ${ }^{10,11)}$.

Several studies investigated the effect of cross training on muscle strength, torque, and dynamic balance but to the best of our knowledge, the value of cross training on repositioning accuracy have not clearly established. The objectives of the current study was to investigate the possible cross effects of an eight weeks proprioceptive training program applied on healthy subjects on twofold: (1) knee joint proprioception accuracy measured using Biodex isokinetic dynamometer and represented by active repositioning test, and (2) balance measured using Biodex balance system and represented by three balance indices.

\section{SUBJECTS AND METHODS}

Sixty healthy subjects aged between 18-30 years were recruited to participate. Inclusion criteria: subjects were included if they were free from any significant history of musculoskeletal, neurological injuries, or had surgery and are willing to participate. Exclusion criteria: subjects were excluded if they have balance or coordination disorders, taking medication on regular basis, using tobacco, or if they suffer from any significant complications of musculoskeletal, neurological, metabolic or vascular disorder of the lower limbs.

This was a randomized controlled trial in which subjects were randomly assigned into training group and control group with thirty subjects in each. The researcher randomized participants using a computer based randomizer program. The researcher has 15 years of experience and was the only one responsible for training \& measurements but was not blinded to the groups' assignment. Proprioception accuracy and balance were measured in both groups at baseline and after 8 weeks of training. The training group (18 male and 12 female) received a proprioceptive training program for the dominant leg only. The control group (20 male and 10 female) did not receive any type of training. The study protocol was explained to every participant and written informed consent was obtained. The study has been approved by the institutional ethical review committee. The Biodex isokinetic system 3 pro (Biodex medical systems, Shirley, NY, USA) was used for all measurements ${ }^{15}$ ) It has shown good reliability and validity for measuring position sense and torque ${ }^{16)}$. Proprioception accuracy was measured through the active repositioning test for the non-dominant joint of every subject in both groups ${ }^{1)}$. It was proved to be a valid and reliable test for proprioception ${ }^{1,2)}$ Subjects were instructed to firstly sit on the chair of the Biodex system with the tested knee positioned in $90^{\circ}$ flexion. The target angle was set at $45^{\circ}$. The blindfolded subjects were instructed to actively reproduce the target joint position at $45^{\circ 2}$. Three trials with the dominant leg were repeated with a rest period of 30 seconds between each. The angular differences between the target angle and the subject's reproduced angle (the absolute error) were recorded in degrees. The absolute error of the target angle was calculated in degrees for each subject before and immediately after training. The deficits in repositioning accuracy were used for statistical analysis. Three trials were recorded.

Balance during single leg stance on the non- dominant leg was assessed by the Biodex balance system which was proved to be a valid and reliable method for measuring balance ${ }^{13}$. The Overall, anterior/posterior and medial/lateral stability indices were measured for each subject before and immediately after training. The ability of subjects to control the tilt angle of the system was calculated as a deviation from the neutral position with time, as well as degrees of deviation with time. A large deviation implies poor neuromuscular response. Three indices were electronically generated: Overall stability index (OSI), antero/posterior stability index (APSI) and medio/lateral stability index (MLSI). Higher value of the stability index in numbers indicates greater challenge in stabilizing the platform. Three trials were carried out with a rest period of one minute between trials. The averages were calculated.

Subjects in the training group received proprioceptive training for the dominant leg only, 3 times per week over a period of 8 weeks while subjects in the control group did not receive any type of training. Rasool and George underpin the exercises that use progressive dynamic balance exercises on a single leg to improve dynamic balance stability ${ }^{12)}$. The proprioceptive training program consisted of six steps: 1. single leg standing on the dominant leg for 30 seconds with leaning forward, backward, and to the sides with eyes opened; 2 . single leg standing on the dominant leg for 30 seconds with leaning forward, backward, and to the sides with eyes closed; 3. single leg training on the rocker board in the antero posterior direction; 4. single leg training on the rocker board in the mediolateral direction; 5. single leg training on the multidirectional wobble balance board; and 6. single leg training on the minitrampoline. Each participant was required to repeat every step once and complete all six steps.

An independent t-test was run to establish baseline equivalency for both groups. Mixed MANOVA was conducted to compare repositioning accuracy and stability indices of pre and post treatment conditions within each group and between both groups. The level of significance was set at $(\mathrm{p} \leq 0.05)$. SPSS 20.0 was the software used for all data analysis. (SPSS Inc. Chicago, IL, USA). 
Table 1. Demographic characteristics of the participants

\begin{tabular}{lcc}
\hline Variables & Training group & Control group \\
\cline { 2 - 3 } & $\mathrm{M} \pm \mathrm{SD}$ & $\mathrm{M} \pm \mathrm{SD}$ \\
\hline Age (years) & $20.2 \pm 3.2$ & $19.6 \pm 1.9$ \\
Male, female (n) & 18,12 & 20,10 \\
Weight $(\mathrm{kg})$ & $74.3 \pm 13.8$ & $77.6 \pm 13.6$ \\
Height $(\mathrm{cm})$ & $171.3 \pm 7.3$ & $172.6 \pm 7.1$ \\
\hline
\end{tabular}

M: Mean; SD: standard deviation

Table 2. Comparison of the pre- and post- training mean values in degrees of both groups

\begin{tabular}{lcccc}
\hline & \multicolumn{2}{c}{ Pre test } & \multicolumn{2}{c}{ Post test } \\
\cline { 2 - 5 } & Training group & Control group & Training group & Control group \\
& $\mathrm{M} \pm \mathrm{SD}$ & $\mathrm{M} \pm \mathrm{SD}$ & $\mathrm{M} \pm \mathrm{SD}$ & $\mathrm{M} \pm \mathrm{SD}$ \\
\hline RA & $4.8 \pm 1.3$ & $4.0 \pm 2.2$ & $2.8 \pm 0.9^{*}$ & $4.1 \pm 1.9$ \\
APSI & $5.5 \pm 2.1$ & $5.1 \pm 1.7$ & $2.6 \pm 0.8^{*}$ & $5.3 \pm 2.0$ \\
MLSI & $3.4 \pm 1.2$ & $3.1 \pm 1.1$ & $2.1 \pm 0.7^{*}$ & $3.1 \pm 1.1$ \\
OSI & $6.4 \pm 2.2$ & $5.9 \pm 1.8$ & $3.9 \pm 1.5^{*}$ & $6.1 \pm 2.2$ \\
\hline
\end{tabular}

M: Mean; SD: standard deviation; p: probability level; RA: repositioning accuracy; APSI: Antero-Posterior Stability Index; MLSI: Medio-Lateral Stability Index; OSI: Overall Stability Index. *Significant: $\mathrm{p}<0.05$.

\section{RESULTS}

Table 1 presents the demographic information for the training and for the control groups. There were no significant differences in age, gender distribution, body mass or height between the two groups $(\mathrm{p}>0.05)$.

There was no significant difference between training and control groups in repositioning accuracy and stability indices pre-treatment $(\mathrm{p}>0.05)$. Post intervention comparison between training group and control group revealed that there was a significant decrease in repositioning accuracy error, APSI, MLSP, and OSI of training group compared with control group $(\mathrm{p}<0.01)$ (Table 2).

There was a significant decrease in the error of repositioning accuracy, APSI, MLSI, and OSI of the training group post treatment compared with pre-treatment $(p<0.001)$, while there was no significant difference in the control group ( $p>0.05$ ) (Table 2).

\section{DISCUSSION}

The current study was designed to investigate the possible cross effects of proprioceptive training on knee proprioception accuracy and on balance in healthy subjects. The findings of the present study showed the superiority of the training group compared with the control group in proprioception accuracy as well as in all stability indices. Several authors have discussed the lack of adequate proprioceptive acuity secondary to capsulo-ligamentous injuries of different joints with subsequent alteration of joints kinematics and consequent pathomechanics that necessitate intensive rehabilitation in order to restore adequate joint mechanics before engaging in sports activities ${ }^{17,18)}$. Muaidi et al. ${ }^{13)}$ reported significant reduction in proprioceptive acuity in participants with unilateral anterior cruciate ligament rupture compared with healthy matched controls. Ellis and Rosenbaum encourraged incorporation of proprioceptive exercises into rehabilitation programme for prevention of recurrent injuries ${ }^{6)}$.

The findings of the present study are in agreement with several studies aimed to improve repositioning accuracy and decrease repositioning absolute error. Fong and $\mathrm{Ng}^{19}$ ) measured the repositioning error of the active knee joint angle in 48 healthy subjects after Tai Chi training. Results showed significant decrease in the repositioning error and better joint position sense. Muaidi et al. ${ }^{13)}$ assured the role of long term training in developing proprioceptive acuity. The study was conducted in a group of anterior cruciate ligament rupture participants and matched controls. Osborne et al. ${ }^{20)}$ studied a group of patients with ankle sprain. Patients received 8 weeks of ankle disc training. Results showed significant improvement in a muscle reaction time of both the experimental as well as the control ankles which was attributed to the potential effect of cross training. The unpredicted movements during proprioceptive training teach the body to react without having to think about these movements. Munn et al. ${ }^{14)}$ measured the cross training effect but in terms of strength. Researchers reported that the average of strength improvement in the untrained side was approximately $7.8 \%$ of its pre-training strength. In the current study, the 
percentage of change in proprioception accuracy and balance of the untrained leg following proprioceptive training was high ( $42 \%$ and $38 \%$ respectively) as compared with the pre-training level. This change could be used efficiently in training of the unaffected limb in case of inability of the affected limb to be trained as in cases of immobilization, acute inflammation and after surgery or injury. Moreover, in the current study subjects were randomized and proprioception gains were compared in the trained and untrained subjects. That randomization eliminated the potential of systematic differences between groups secondary to allocation bias.

Multiple studies discussed the neurophysiologic explanations behind the positive cross training effect on the untrained limb. Carroll et al. ${ }^{10)}$ mentioned that the cross training effect can be achieved in the contralateral homologous muscles. The effect is attributed to the increased motor neuron output with subsequent spillover to the control system of the contralateral limb. Lee et al. ${ }^{11)}$ attributed the cross training effect to the increase of neural drive from motor cortex and cortical voluntary activation. Hortobagyi ${ }^{21)}$ stated that there is possibility that cross education is mediated by cross-spinal path. Also, the contralateral elements of the central nervous system play a functional role, through adaptation or cross education, in affecting the motor output of the contralateral homologous muscle.

Carroll et al. ${ }^{10)}$ pointed out the involvement of cortical, subcortical and spinal levels in the facilitation of transfer of strength from one side to the contralateral side. Researchers discussed the central mechanism through the adaptations in the control system of the trained limb and the spillover to the control system for the contralateral limb. Kofotolis and Kellis ${ }^{3)}$ emphasized the role of cross training effect of proprioceptive training on the knee torque of the immobilized contralateral leg.

Regarding balance stability; Treleaven et al. ${ }^{22}$ reported that joint position error has high positive prediction value to determine balance disorders. Rasool and George ${ }^{12)}$ studied thirty healthy male athletes to investigate the effect of dynamic balance training on dynamic stability. Participants received progressive one-leg dynamic balance training. Star excursion balance test was the main outcome measure. Results showed significant, even for a smaller extent, improvement in dynamic stability performance in the untrained leg. Malliou et al. ${ }^{17)}$ studied 100 young soccer players aiming to investigate the effect of balance training on proprioception ability and on lower limb injuries. Results showed improvement in proprioception and significant reduction in lower limb injuries. Irrgang et al. ${ }^{18)}$ confirmed the role of balance and proprioceptive training to restore motor control of the lower extremities.

Limitations of this study are the lack of homogeneity of the subjects in terms of activity level and the assessor of the outcome variables was aware of group's assignment. Shortcomings also include the potential influence of participants' motivation on the quality of proprioceptive assessment. The assessor tried to control the influence of motivation through verbal encouragement during testing. Future studies are warranted to explore the effect of proprioceptive cross training in patients and after surgeries.

In conclusion, proprioceptive training for 8 weeks had significant cross effects in improving proprioceptive accuracy and balance in healthy subjects. The proprioceptive training program used in the current study is effective, feasible and could be considered by clinicians to incorporate into the rehabilitation program.

The authors recommend benefiting from the new advances in robotic devices; that have adequate sensitivity and reliability in detecting small differences in proprioceptive acuity ${ }^{23}$. Also, we recommend investigating proprioceptive acuity in different subgroups of patients.

\section{REFERENCES}

1) Contu S, Cappello L, Konczak J, et al.: Preliminary analysis of non-dominant proprioceptive acuity and interlimb asymmetry in the human wrist. Conf Proc IEEE Eng Med Biol Soc, 2015, 2015: 3598-3601. [Medline]

2) Elangovan N, Herrmann A, Konczak J: Assessing proprioceptive function: evaluating joint position matching methods against psychophysical thresholds. Phys Ther, 2014, 94: 553-561. [Medline] [CrossRef]

3) Kofotolis ND, Kellis E: Cross-training effects of a proprioceptive neuromuscular facilitation exercise programme on knee musculature. Phys Ther Sport, 2007, 8: 109-116. [CrossRef]

4) Lin DH, Lin CH, Lin YF, et al.: Efficacy of 2 non-weight-bearing interventions, proprioception training versus strength training, for patients with knee osteoarthritis: a randomized clinical trial. J Orthop Sports Phys Ther, 2009, 39: 450-457. [Medline] [CrossRef]

5) Fuentes CT, Bastian AJ: Where is your arm? Variations in proprioception across space and tasks. J Neurophysiol, 2010, 103: 164-171. [Medline] [CrossRef]

6) Eils E, Rosenbaum D: A multi-station proprioceptive exercise program in patients with ankle instability. Med Sci Sports Exerc, 2001, 33: 1991-1998. [Medline] [CrossRef]

7) Thomas SG, Pagura SM, Kennedy D: Physical activity and its relationship to physical performance in patients with end stage knee osteoarthritis. J Orthop Sports Phys Ther, 2003, 33: 745-754. [Medline] [CrossRef]

8) Levinger P, Menz HB, Morrow AD, et al.: Lower limb proprioception deficits persist following knee replacement surgery despite improvements in knee extension strength. Knee Surg Sports Traumatol Arthrosc, 2012, 20: 1097-1103. [Medline] [CrossRef]

9) Jan MH, Tang PF, Lin JJ, et al.: Efficacy of a target-matching foot-stepping exercise on proprioception and function in patients with knee osteoarthritis. J Orthop Sports Phys Ther, 2008, 38: 19-25. [Medline] [CrossRef]

10) Carroll TJ, Herbert RD, Munn J, et al.: Contralateral effects of unilateral strength training: evidence and possible mechanisms. J Appl Physiol 1985, 2006, 101: 1514-1522. [Medline] [CrossRef]

11) Lee M, Gandevia SC, Carroll TJ: Unilateral strength training increases voluntary activation of the opposite untrained limb. Clin Neurophysiol, 2009, 120 : 
802-808. [Medline] [CrossRef]

12) Rasool J, George K. The impact of single-leg dynamic balance training on dynamic stability. Physical therapy in sports, 2007, 8: 177-184. [CrossRef]

13) Muaidi QI, Nicholson LL, Refshauge KM, et al.: Effect of anterior cruciate ligament injury and reconstruction on proprioceptive acuity of knee rotation in the transverse plane. Am J Sports Med, 2009, 37: 1618-1626. [Medline] [CrossRef]

14) Munn J, Herbert RD, Gandevia SC: Contralateral effects of unilateral resistance training: a meta-analysis. J Appl Physiol 1985, 2004, 96: 1861-1866. [Medline] [CrossRef]

15) Seo HD, Kim MY, Choi JE, et al.: Effects of Kinesio taping on joint position sense of the ankle. J Phys Ther Sci, 2016, 28: 1158-1160. [Medline] [CrossRef]

16) Drouin JM, Valovich-mcLeod TC, Shultz SJ, et al.: Reliability and validity of the Biodex system 3 pro isokinetic dynamometer velocity, torque and position measurements. Eur J Appl Physiol, 2004, 91: 22-29. [Medline] [CrossRef]

17) Malliou P, Gioftsidou A, Pafis G, et al.: Proprioceptive training (balance exercises) reduces lower extremity injuries in young soccer players. J Back Musculoskeletal Rehabil, 2004, 17: 101-104.

18) Irrgang JJ, Whitney SL, Cox ED: Balance and proprioceptive training for rehabilitation of the lower extremity. JSR, 1994, 3: 68-83. [CrossRef]

19) Fong SM, Ng GY: The effects on sensorimotor performance and balance with Tai Chi training. Arch Phys Med Rehabil, 2006, 87: 82-87. [Medline] [CrossRef]

20) Osborne MD, Chou LS, Laskowski ER, et al.: The effect of ankle disk training on muscle reaction time in subjects with a history of ankle sprain. Am J Sports Med, 2001, 29: 627-632. [Medline]

21) Hortobágyi T: Cross education and the human central nervous system. IEEE Eng Med Biol Mag, 2005, 24: 22-28. [Medline] [CrossRef]

22) Treleaven J, Jull G, LowChoy N: The relationship of cervical joint position error to balance and eye movement disturbances in persistent whiplash. Man Ther, 2006, 11: 99-106. [Medline] [CrossRef]

23) Cappello L, Elangovan N, Contu S, et al.: Robot-aided assessment of wrist proprioception. Front Hum Neurosci, 2015, 9: 198. [Medline] [CrossRef] 